\title{
Community Pharmacists Knowledge, Behaviours and Practice of Adverse Drug Reactions Reporting in Lagos State, Nigeria.
}

\author{
Stella Folajole Usifoh", Isabel Naomi Aika, Valentine Uche Odili, Jerome Onyisi Nwokoro \\ Department of Clinical Pharmacy and Pharmacy Practice, Faculty of Pharmacy, University of Benin, Benin City. NIGERIA.
}

\begin{abstract}
Introduction: Adverse Drug Reaction (ADR) reporting is essential to ensure safe use of medication. Objective: To assess community pharmacists' knowledge, behaviours and practice of ADR reporting in Lagos State. Methods: This was a cross-sectional survey using self-administered questionnaire distributed to randomly selected pharmacists in retail community pharmacies in Lagos State. The instrument is a 62 item structured questionnaire in four sections; the demographics, knowledge about ADR reporting system, assessment of practice and attitude on ADR reporting; and the behavior and practice of patients counseling about ADR by community pharmacists. Data analysis was done with Statistical Package for the Social Sciences (SPSS) version 20. Results: Majority (31.9\%) of the respondents have practiced in community pharmacies for less than 5 years, $62.7 \%$ of the community pharmacists were familiar with adverse drug reaction reporting. $57.8 \%$ of the pharmacists have internet facility in their pharmacies and $79.4 \%$ of the respondents were aware that community pharmacists can submit adverse drug reactions online. In the preceding months, $78.4 \%$ of the pharmacists had encountered many serious ADR but only $27.0 \%$ reported them. The reasons for underreporting of ADR included uncertainty about causality (52.0\%), respondents not sure of which ADR to report (38.2\%), no access to reporting forms $(33.8 \%)$, ignorance of the rule of reporting $(30.4 \%)$, and complexity of the reporting forms $(16.2 \%)$. Conclusion: There is low reporting of adverse drug reactions by community pharmacists attributable to insufficient knowledge and high level of untrained community pharmacists in pharmacovigilance and adverse drug reactions reporting.
\end{abstract}

Key words: Adverse drug reaction (ADR); Community pharmacists; Pharmacovigilance; Reporting.

\section{INTRODUCTION}

Drugs used in man for prophylaxis, diagnosis or therapy of disease and for the modification of physiological function may produce unexpected adverse reactions. Consequently, rapid detection of these reactions is very important such that unintended hazards are promptly identified and appropriate regulatory action taken to ensure the safe use of medications.

WHO defined adverse drug reactions (ADR) as "any response to a drug which is noxious and unintended that occurs at doses normally used in man for prophylaxis, diagnosis or therapy of disease or for the modification of physiological function". ${ }^{1}$ While pharmacovigilance is the science and activities relating to the detection, assessment, understanding and prevention of adverse effects of drugs or any other drugrelated problems. ADR is one of the causes of hospital admissions with an increase in morbidity and mortality. ${ }^{2,3}$ According to Roughead (1998) ADR account for about $5 \%$ of all hospital admissions. ${ }^{4}$ Severity of ADR is a subjective assessment made by the patient and/or the healthcare professional which is useful in identification of reactions that may affect adherence or that needs prompt intervention. Huge economic loss has been associated with $\mathrm{ADR}^{3}$ with an increase length of hospital stay which consequently increase in health care cost. Monitoring of adverse drug reactions after drug marketing is vital because not all ADR can be recognized from early studies carried out by the manufacturer. ${ }^{5,6}$
DOI: 10.5530/ijopp.11.1.3

Address for correspondence: Dr. Stella F. Usifoh Ph. D, Department of Clinical Pharmacy and Pharmacy Practice, Faculty of Pharmacy, University of Benin, Benin City. NIGERIA.

Phone : +234-8056226668

Email Id: sfusifoh@uniben.edu

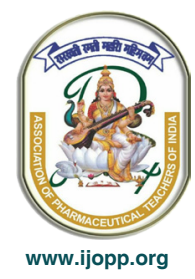


Spontaneous reporting systems of detecting adverse drug reactions, out of the several methods have contributed significantly to improve the levels of pharmacovigilance in many countries. ${ }^{7}$ Thus, the importance of healthcare workers in the area of spontaneous reporting of adverse drug reactions and development of its databases worldwide has been established.,

However, under-reporting of adverse drug reactions is a major obstacle for the progress of pharmacovigilance programs despite the better reporting culture of the developed nations. ${ }^{10,11}$ Previous studies reported a strong association between adverse drug reactions reporting and knowledge, attitude and practice of the healthcare professionals. ${ }^{6,14,13,15}$ Therefore to establish and improve Pharmacovigilance program in any country, improving the knowledge, attitude and practice of health professional is essential. ${ }^{16,13}$

Community Pharmacists (CPs) as part of their pharmaceutical care functions have roles and professional responsibilities to monitor the safety of medicines for which they are sole custodians. ${ }^{19}$ CPS are an important source of adverse drug reaction reporting because they are the first to be contacted by patients in most adverse drug reaction cases. ${ }^{4}$ CPs can play an important role in adverse drug reactions reporting by increasing the number and the quality of submitted report. ${ }^{17,18}$

However, in many countries, the knowledge of pharmacists about adverse drug reaction reporting is poor and the rate of reporting is low. ${ }^{20,21}$ Thus assessing the knowledge, behaviors and practice of community pharmacists relating to spontaneous reporting of adverse drug reactions is vital because when pharmacists have sufficient knowledge of ADR, they can have a positive impact on other health care professionals.

This study aims to assess community pharmacist's knowledge, behaviors and practice of adverse drug reaction reporting as well as identify factors influencing the reporting of adverse drug reactions in Lagos State.

\section{METHODS}

This was a retrospective cross-sectional study of retail community pharmacies in Lagos state, Nigeria. The state is divided into 56 Local Council Development Areas and there are about 1500 registered community pharmacies with 900 of them as retail pharmacies. A sample of 270 was calculated using Raosoft ${ }^{\circledR}$ sample size calculator with $95 \%$ confidence level $5 \%$ margin of errors and $50 \%$ confidence interval, but a sample of 300 was used to make room for attrition. A random sampling technique was used to select one out of every three registered pharmacies. The inclusion criteria were registered retailed consenting community pharmacists who were always on duty during opening hours. While pharmacists who were in wholesale and distribution and those in retail practice who were frequently not available during opening hours were excluded from the study.

The data collection instrument used for this study was a 62 item structured self-administered questionnaire divided into four sections which include; demographic details of the pharmacists, knowledge about ADR reporting system in Nigeria and assessment of practice and attitude and knowledge on ADR; the behavior and practice of ADR reporting and patient counseling about ADR by community pharmacists Data were entered into Microsoft Excel data sheets, cross-checked, loaded and analyzed using SPSS version 20.0 (SPSS, Atlanta, GA, USA). Descriptive statistics were computed for continuous variables and results presented as frequencies and percentages. Inferential statistical method used was chi-square while comparisons between groups were evaluated with Student unpaired t- test, $\mathrm{p}$ values $<0.05$ were considered significant.

\section{RESULTS}

Of the 300 questionnaires distributed, 204 were completed and returned within the stipulated time frame giving a response rate of $68 \%$. The majority of the respondents $112(55 \%)$ were in the age bracket of 30- 49 years while few of the respondents $7(3.4 \%)$ were 60 years and above. Most of the respondents were males 103 (50.0\%). The majority 159 (77.5\%) had a Bachelor of Pharmacy (B Pharm) degree and 125 (61.3\%) were trained in Nigeria. Table 1. Majority of the respondents $137(67.2 \%)$ dispensed less than 20 prescriptions per day in their pharmacies. The number of patients attended to per day were less than 30 for many of the respondents $81(39.7 \%)$ while the average time spent on each patient by majority of the respondents $180(87.3 \%)$ was $<15$ min. More than half of the respondents 118 (57.8\%) had internet services available in their pharmacies and $128(62.7 \%)$ were familiar with ADR reporting. (Table 1).

Table 2 displays responses of CPs on practice and attitude towards ADR reporting. Many (47.1\%) of the respondents noted they had inadequate knowledge of adverse drug reactions and the majority (53.4\%) strongly agreed that they required better training in identification of adverse drug reactions. Majority 197 (96.5\%) of respondents also agreed that they require improved or additional knowledge in adverse drug reactions reporting. Similarly, $125(61.2 \%)$ of the respondents disagreed that their level of knowledge in adverse drug reactions was sufficient and satisfactory.

Majority of the respondents $(82.8 \%)$ had good knowledge of ADR with a mean score of $18.87 \pm$ SD 4.016 
Table1: Demographics and practice of respondents

\begin{tabular}{|c|c|c|}
\hline Variables & & Frequency (\%) \\
\hline \multirow[t]{5}{*}{ Age (years) } & $20-29$ & $46(22.5)$ \\
\hline & $30-39$ & $56(27.5)$ \\
\hline & $40-49$ & $56(27.5)$ \\
\hline & $50-59$ & $38(18.6)$ \\
\hline & $>60$ & $7(3.4)$ \\
\hline \multirow[t]{2}{*}{ Gender } & Male & $103(50.5)$ \\
\hline & Female & $90(44.1)$ \\
\hline \multirow[t]{5}{*}{ Years of graduation } & $1-5$ & $50(24.5)$ \\
\hline & $6-10$ & $39(19.1)$ \\
\hline & $11-15$ & $26(12.7)$ \\
\hline & $16-20$ & $24(11.8)$ \\
\hline & $>21$ & $64(31.4)$ \\
\hline \multirow[t]{6}{*}{ Level of education } & Diploma & $15(7.4)$ \\
\hline & B.Pharm & $158(77.5)$ \\
\hline & Pharm.D & $6(2.9)$ \\
\hline & FPCPharm & $6(2.9)$ \\
\hline & Masters & $11(5.4)$ \\
\hline & Ph.D & $4(2.0)$ \\
\hline \multirow{5}{*}{$\begin{array}{l}\text { Country of } \\
\text { Qualification }\end{array}$} & Europe & $3(1.5)$ \\
\hline & America & $3(1.5)$ \\
\hline & Asia & $0(0.0)$ \\
\hline & Africa & $67(32.8)$ \\
\hline & Nigeria & $125(61.3)$ \\
\hline \multirow{4}{*}{$\begin{array}{l}\text { Years of practice } \\
\text { as a community } \\
\text { pharmacist }\end{array}$} & $<5$ & $66(32.4)$ \\
\hline & $6-10$ & $45(22.1)$ \\
\hline & $11-15$ & $38(18.6)$ \\
\hline & $>15$ & $53(26.0)$ \\
\hline \multirow{2}{*}{$\begin{array}{c}\text { Number of } \\
\text { prescription } \\
\text { dispensed per day }\end{array}$} & $<20$ & $137(67.2)$ \\
\hline & $>20$ & $59(28.9)$ \\
\hline \multirow{3}{*}{$\begin{array}{l}\text { Number of patients } \\
\text { served per day }\end{array}$} & $<30$ & $81(39.7)$ \\
\hline & $31-50$ & $65(31.9)$ \\
\hline & $>50$ & $52(25.5)$ \\
\hline \multirow{3}{*}{$\begin{array}{l}\text { Time spent with each } \\
\text { patient (minutes) }\end{array}$} & $<5$ & $55(27.0)$ \\
\hline & $5-15$ & $127(62.3)$ \\
\hline & $>15$ & $9(4.4)$ \\
\hline
\end{tabular}

out of a maximum of 28 and were conversant with the different classes of drugs that can cause ADR such as aminoglycosides, antineoplastic, corticosteroids, thrombolytic agents, cardiac glycosides, sulphonamides, penicillin's and anticonvulsants. However, majority, $113(55.4 \%)$ of the respondents erroneously classified side effects of drugs as adverse drug reactions. Some $58(28.4 \%), 53(26.0 \%)$ and $71(34.8 \%)$ respondents wrongly identified drug withdrawal syndrome, drug abuse, and accidental poisoning respectively as ADRs. Similarly, only $155(76 \%)$ respondents knew that the National Agency for Food Drugs Administration and Control (NAFDAC) is the agency that regulates adverse drug reactions reporting in Nigeria. (Table 3).

Most of the respondents $138(67.6 \%)$ do not report ADR. Even though most 160 (78.4\%) have encountered serious ADRs in the previous 12 months. The respondents identified the following factors among others as contributing to their non-reporting of ADRs; uncertainty about the causality of ADR $52.0 \%$; not sure of the ADR to report $38.2 \%$; non-accessibility to ADR reporting form $33.8 \%$; ignorance of the rule of reporting $30.4 \%$. Table 4.

The experiences and actions employed by pharmacists in the management of ADR when a patient sought advice from them were varied. The common approaches employed by most of the respondents to manage patients suffering from ADRs were to refer the patient to see the physician, $(78.9 \%)$ and recommend medication and ask the patient to stop taking the medication causing the ADR $(86.8 \%)$.

Table 5 displays the relationship between demographics and the knowledge of ADR. Respondents who were within the age range of 20-29 years, were recent graduates (1-5) years, and those who were trained in Nigeria had significantly higher knowledge about ADR. $\mathrm{p}<0.05$.

Table 6 represents some pertinent questions asked by the respondents during counseling and drug use in other to prevent ADRs. $49.5 \%$ of respondents always asked patients about their allergic history to certain medications. $68.1 \%$ of respondents always asked female patients about their pregnancy status, while 46.1\% always asked female patients if they are nursing a child. Only a few of the respondents $7.8 \%$ reported that they always discuss ADRs with other pharmacists.

\section{DISCUSSION}

The findings from this study reveal that though the respondents had a good knowledge of adverse drug reactions but they were poor at reporting the incidences. Previous studies have shown that the rate of reporting ADRs by pharmacists in different countries varied from $3 \%$ to $14.7 \%$ which is lower than what was reported in this study. ${ }^{20,23}$ The reasons for the pharmacists nonreporting of adverse drug reactions mainly included uncertainty about causality, not sure of the adverse drug reactions to report, not having access to adverse drug reactions reporting form, ignorance of the rule of reporting, the complexity of the form, lack of time and workload. The determinants of under-reporting of 


\begin{tabular}{|c|c|c|c|c|c|}
\hline Item questions & $\begin{array}{c}\text { Strongly } \\
\text { disagree } \\
\text { N (\%) }\end{array}$ & $\begin{array}{l}\text { Disagree } \\
\quad \mathrm{N}(\%)\end{array}$ & $\begin{array}{l}\text { Neutral } \\
\text { N (\%) }\end{array}$ & $\begin{array}{l}\text { Agree } \\
\mathrm{N}(\%)\end{array}$ & $\begin{array}{c}\text { Strongly } \\
\text { agree } \\
\text { N (\%) }\end{array}$ \\
\hline I consider my knowledge of ADR to be adequate & $2(1.0)$ & $96(47.1)$ & $33(16.2)$ & $63(30.9)$ & 10(4.9) \\
\hline I can be better trained in identifying ADR & $2(1.0)$ & $3(1.5)$ & $6(2.9)$ & $24(41.2)$ & $109(53.4)$ \\
\hline $\begin{array}{l}\text { I require improved or additional knowledge in ADR } \\
\text { reporting }\end{array}$ & $2(1.0)$ & $0(0.0)$ & $5(2.5)$ & $87(42.6)$ & $110(53.9)$ \\
\hline $\begin{array}{c}\text { My level of knowledge in ADR is sufficient and } \\
\text { satisfactory }\end{array}$ & $6(2.9)$ & $119(58.3)$ & $30(14.7)$ & $45(22.1)$ & $4(2.0)$ \\
\hline
\end{tabular}

\begin{tabular}{|c|c|c|c|}
\hline \multicolumn{2}{|r|}{ Variables } & \multicolumn{2}{|c|}{ Frequency (\%) } \\
\hline & & Yes & No \\
\hline $\begin{array}{l}\text { Can CPs submit ADRs report } \\
\text { online in Nigeria }\end{array}$ & & $162(79.4)$ & $41(20.1)$ \\
\hline Is side effects an ADR & & $92(45.1)$ & $110(53.9)$ \\
\hline \multirow[t]{6}{*}{ Who regulates ADR reporting } & Pharmacist Council of Nigeria & $2(1.0)$ & $202(99.0)$ \\
\hline & Pharmaceutical Society Nigeria & $28(13.7)$ & $175(85.8)$ \\
\hline & $\begin{array}{c}\text { National Institute for Pharmaceutical Research and } \\
\text { Developments }\end{array}$ & $7(3.4)$ & $166(81.4)$ \\
\hline & Association of Community Pharmacist of Nigeria & $8(3.9)$ & $158(77.5)$ \\
\hline & National Agency for Food Drugs Administration and Control & $155(76.0)$ & $2(1.0)$ \\
\hline & Federal Ministry of Health & $3(1.5)$ & $201(98.5)$ \\
\hline \multirow{4}{*}{$\begin{array}{c}\text { Are any of these reactions } \\
\text { classified as ADR }\end{array}$} & Drug withdrawal & $58(28.4)$ & $145(71.1)$ \\
\hline & Drug abuse syndrome & $53(26.0)$ & $150(73.5)$ \\
\hline & Accidental poison & $71(34.8)$ & $132(64.7)$ \\
\hline & Side effects of medications & $113(55.4)$ & $91(44.6)$ \\
\hline \multirow{4}{*}{$\begin{array}{l}\text { Which group of patients are } \\
\text { susceptible to ADRs }\end{array}$} & Pediatrics & $182(90.2)$ & $19(8.3)$ \\
\hline & Geriatrics & $184(90.2)$ & $17(8.5)$ \\
\hline & Patients with organ damage & $185(91.6)$ & $17(8.4)$ \\
\hline & Patients receiving multiple drugs & $200(98.0)$ & $3(1.5)$ \\
\hline
\end{tabular}

\section{Table 4: Respondents behavior and practice towards ADR}

\begin{tabular}{|c|c|c|c|}
\hline \multirow[t]{2}{*}{ Items question } & & \multicolumn{2}{|c|}{ Frequency $\mathbf{N}(\%)$} \\
\hline & & Yes & No \\
\hline \multicolumn{4}{|c|}{$\begin{array}{l}\text { Do you report ADR that you come across? } \\
55(27.0)\end{array}$} \\
\hline & & $138(67.6)$ & \\
\hline & \multicolumn{3}{|l|}{ Reasons for not reporting ADR } \\
\hline & Uncertainty about causality & $106(52.0)$ & $60(29.4)$ \\
\hline & Not sure of the ADR to report & $78(38.2)$ & $88(43.1)$ \\
\hline & Access to ADR reporting form & $69(33.8)$ & $97(47.5)$ \\
\hline & Ignorant of the rule of reporting & $62(30.4)$ & $100(49.0)$ \\
\hline & Did not know that ADR should be reported & $14(6.9)$ & $153(75.0)$ \\
\hline & Lack of time and workload & $32(15.7)$ & $139(68.1)$ \\
\hline & Complexity of the form & $33(16.2)$ & $135(66.2)$ \\
\hline & Fear of malpractice suit & $14(6.9)$ & $154(75.5)$ \\
\hline & In the last month have you encounter any ADRs & $25(12.3)$ & $167(81.9)$ \\
\hline & In the last 12 months have you encountered any serious ADRs. & $160(78.4)$ & $1(0.5)$ \\
\hline
\end{tabular}


Table 5: Relationship between demographics and knowledge of ADRs

\begin{tabular}{|c|c|c|c|c|}
\hline Variables & & $\mathbf{N}$ & Mean \pm SD & P-value \\
\hline \multirow[t]{5}{*}{ Age in years } & $20-29$ & 46 & $21.00 \pm 2.724$ & 0.0011 \\
\hline & $30-39$ & 56 & $18.09 \pm 4.457$ & \\
\hline & $40-49$ & 56 & $18.68 \pm 3.871$ & \\
\hline & $50-59$ & 38 & $18.08 \pm 3.900$ & \\
\hline & $>60$ & 7 & $17.29 \pm 5.251$ & \\
\hline \multirow[t]{2}{*}{ Gender } & Male & 103 & $18.92 \pm 3.798$ & \\
\hline & Female & 90 & $19.52 \pm 3.670$ & 0.2755 \\
\hline \multirow[t]{5}{*}{ Year of graduation } & 1-5years & 50 & $21.06 \pm 2.198$ & \\
\hline & $6-10$ years & 39 & $17.46 \pm 4.751$ & \\
\hline & 11-15years & 26 & $18.04 \pm 4.565$ & $<0.0001$ \\
\hline & 16-20years & 24 & $19.96 \pm 3.507$ & \\
\hline & >20years & 64 & $17.88 \pm 3.844$ & \\
\hline \multirow[t]{6}{*}{ Level of education } & Diploma & 15 & $20.93 \pm 2.685$ & \\
\hline & BPharm & 158 & $18.74 \pm 4.082$ & 0.158 \\
\hline & PharmD & 6 & $17.50 \pm 5.167$ & \\
\hline & FPCPharm & 6 & 21.002 .191 & \\
\hline & MSc & 11 & $17.45 \pm 4.275$ & \\
\hline & $\mathrm{PhD}$ & 4 & $18.25 \pm 4.016$ & \\
\hline \multirow[t]{4}{*}{ Country of qualification } & Europe & 3 & $16.67 \pm 4.146$ & \\
\hline & America & 3 & $20.00 \pm 7.000$ & \\
\hline & Africa & 67 & $17.24 \pm 4.145$ & \\
\hline & Nigeria & 125 & $19.79 \pm 3.617$ & 0.0002 \\
\hline \multirow[t]{3}{*}{ Number of prescription dispensed/day } & $<20$ & 137 & $18.55 \pm 3.732$ & \\
\hline & $21-30$ & 23 & $18.57 \pm 5.177$ & \\
\hline & $>30$ & 36 & $20.31 \pm 4.125$ & 0.6850 \\
\hline \multirow[t]{3}{*}{ Time spent with each patients } & $<5$ minutes & 55 & $18.69 \pm 4.100$ & \\
\hline & 5-15minutes & 127 & $19.12 \pm 3.997$ & \\
\hline & $>15$ minutes & 9 & $18.22 \pm 3.528$ & 0.0607 \\
\hline
\end{tabular}

Table 6: Respondents method of counseling and drug used in the management of ADR

\begin{tabular}{|c|c|c|c|c|c|}
\hline Item questions & $\begin{array}{l}\text { Never } \\
\text { N (\%) }\end{array}$ & $\begin{array}{l}\text { rarely } \\
\mathrm{N}(\%)\end{array}$ & $\begin{array}{l}\text { Sometimes } \\
\mathbf{N}(\%)\end{array}$ & $\begin{array}{l}\text { frequently } \\
\text { N (\%) }\end{array}$ & $\begin{array}{l}\text { always } \\
\mathrm{N}(\%)\end{array}$ \\
\hline $\begin{array}{l}\text { How often do you ask a patient, if he/she is allergic to } \\
\text { medication }\end{array}$ & $3(1.5)$ & $32(15.7)$ & $28(13.7)$ & $40(19.6)$ & 101(49.5) \\
\hline $\begin{array}{c}\text { How often do you ask a female patients if she is pregnant when } \\
\text { dispensing teratogenic/abortive medication }\end{array}$ & $4(2.0)$ & $2(1.0)$ & $19(9.3)$ & $40(19.6)$ & 136(68.1) \\
\hline $\begin{array}{l}\text { How often do you ask a female patient if she is lactating when } \\
\text { dispensing medication that is excreted in the mother's milk that } \\
\text { might harm the baby }\end{array}$ & $4(2.0)$ & $2(1.0)$ & $32(15.7)$ & $72(35.5)$ & $94(46.1)$ \\
\hline $\begin{array}{l}\text { How often do you discuss an ADRs with your pharmacist } \\
\text { colleague }\end{array}$ & $3(1.5)$ & $59(28.9)$ & $107(52.5)$ & $19(9.3)$ & $16(7.8)$ \\
\hline
\end{tabular}

adverse drug reactions as shown from our study is in line to a large extent with other reports from Nigeria, China, Spain, and Malaysia. 15,22,24,25

In this study, some of the respondents did not know the regulatory agency for pharmacovigilance in Nigeria and their knowledge about adverse drug reactions was Indian Journal of Pharmacy Practice, Vol 11, Issue 1, Jan-Mar, 2018 inadequate. Patient untoward reactions due to drug withdrawal, drug abuse, accidental poisoning and side effects of drugs were wrongly classified as ADRs. ${ }^{26}$ This gap in knowledge will impede pharmacists' recognition of ADRs. It is important that pharmacists be familiar with the agency in charge of pharmacovigilance and the procedure for ADR reporting as this aids ADR reporting 
practice. This gap in knowledge may be the reason why more than half of the respondents were willing to undergo training to help them identify and improve ADRs reporting. These findings advocate the need for awareness programs and continuing educational programs for community pharmacists since they are an important source of ADR reporting and are usually the first port of call by patients in most cases of adverse drug reactions. ${ }^{4}$ Interventional programs have been shown to increase the knowledge and awareness of adverse drug reactions reporting in other countries. ${ }^{18,25}$ Electronic reporting will expedite reporting process due to delays in forms submission and forms misplacement, CPs access to internet in their premises will promote ADRs reporting practice.

The respondents see $<20$ prescriptions and recommend medications for $<30$ patients daily. This shows that if properly trained, they can play an important role in identifying and reporting ADRs. The common approaches perceived by the community pharmacists to manage patients suffering from adverse drug reactions were mainly to prescribe medication and to ask the patient to stop taking medication causing the adverse drug reactions. The role of CPs as part of the health care team is to advise on drug use or recommend medication or ask the patients to stop the medication known to cause the adverse drug reactions. ${ }^{27}$ This is a common practice among our respondents, although they were not asked about follow-up and the patient's response to the intervention, thus adequately training to detect, manage mild cases, report ADRs and prompt referrals to physicians life-threatening is important. Patients at risk of suffering from adverse drug reaction should be identified and promptly protected. High- risk patients include pregnant/lactating women, pediatrics, geriatrics, patients with organ failure and those on polypharmacy. ${ }^{28}$ From the study, the majority of the respondents frequently counseled their female patients on allergic medication, pregnant women on teratogenic or abortive medications and lactating mothers on medications that are excreted in breast milk. These patients should be denied of high-risk medications and when such medications must be given, they should be closely monitored.

Limitation of the study: The accuracy of the recall and personal bias of respondents, opinions of nonresponders in general and participants who did not respond to some aspects of the questionnaires could have affected the interpretation.

\section{CONCLUSION}

Adverse Drug Reactions reporting using the spontaneous ADR reporting form is low among community pharmacists in Lagos state attributable to the high level of untrained community pharmacists in pharmacovigilance and ADR reporting. Pharmacist knowledge and attitude are significant in adverse drug reactions reporting. This study highlights the urgent need for incorporation of ADR reporting concepts in the educational curriculum; training of $\mathrm{CPs}$ in $\mathrm{ADR}$ reporting is necessary for achieving safety goals, safeguarding public health and strengthening the pharmacovigilance activities.

\section{ACKNOWLEDGMENT}

The authors wish to thank the Association of Community Pharmacist Lagos state chapter and all the pharmacists that participated in the study.

\section{CONFLICT OF INTEREST}

Authors declare none

\section{ABBREVIATION USED}

$\mathrm{ADR}=$ Adverse Drug Reactions, $\mathrm{CP}=$ Community Pharmacists, NAFDAC $=$ National Agency for Food Drug Administration and Control

\section{SUMMARY}

There is low reporting of adverse drug reactions by community pharmacists due to poor knowledge and lack of training of community pharmacists in pharmacovigilance and adverse drug reactions reporting.

\section{REFERENCES}

1. World Health Organization. Safety of Medicines. A guide to detecting and reporting of adverse drug reactions. Geneva, Switzerland. World Health Organization. 2002. WHO/EDM/QSM/2.

2. Pirmohamed M, James S, Meakin S, Green C, Scott A, Walley T, et al. Adverse Drug Reactions as the cause of admission to hospital prospective analysis of 18,820 patients. BMJ 2004;329(7456):15-9.

3. Patel KI, Kedia MS, Bajpai D, Mehta SS, Kshirsagar NA, Gegtay NJ. Evaluation of the prevalence and economic burden of adverse drug reactions presenting of a tertiary referral centre a prospective study. BMC Clinical Pharmacology. 2007;7(1):7-8.

4. Roughead EE, Gilbert AL, Primrose JG. Drug-related hospital admissions: a review of Australian studies published 1988-1996. Med J Aust. 1998;165:405-8.

5. Elkaimi RM, Hassali MA, Ibrahim MIM, Widodo RT, Efan QM, Hadi MA. Pharmacy students' knowledge and perception about pharmacovigilance in Malaysian Public Universities. AM J Pharm Educ. 2011;75(5):96.

6. Stricker BH, Psaty BM. Detection, verification, and quantification of adverse drug reactions. Br Med J. 2001;329 (7456):44-7

7. Kharkar M, Bowalekar S. Knowledge, attitude and perception/Practices (KAP) of medical practitioners in India towards adverse drug reaction (ADR) reporting. Perpect Clin Res. 2012;3(3):90-4.

8. Walter PC. Making the most of spontaneous adverse drug reaction reporting. Basic Clinpharmacol Toxicol. 2006;98(3):320-3.

9. Valano A, Cereza G, Pedros C, Agusti A, Danes I, Aguilera C, et al. Obstacles and solutions for spontaneous reporting of adverse drug reaction in the hospital. Br J ClinPharmacol. 2005;60(6):653-8. 
10. ULfvarson J, Mejyr S, Bengman U. Nurses are increasingly involved in pharmacovigilance in Sweden. Pharmacoepidemiol Drug Saf. 2007;16(5):532-7.

11. Williams D, Feely J. Under reporting of adverse drug reaction attitude of Iris doctors. Ir J Med Sci. 1999;168:257-61.

12. Lopez Gonzalesz E, Herdeiro MT, Figueiras A. Determinants of under-reporting of adverse drug reactions: a systematic review. Drug Saf. 2009;32(1):19-31.

13. Sweis $D$, Wong IC. A survey on factors that could affect adverse drug reaction reporting according to hospital Pharmacists in Great Britain. Drug Saf. 2000;23(2):165-72.

14. Herdeiro MT, Figueiras A, Polnia J, Gestal-Otero JI. Physicians Attitude and Adverse drug Reaction Reporting. Drug Saf. 2005;28(9):825-33.

15. Bawazir SA. Attitude of Community Pharmacists in Saudi Arabia towards adverse drug reaction reporting. Saudi Pharm J. 2006;14(1):75-83.

16. Aziz Z, Siang TE, Badarudin NS. Reporting of adverse drug reactions: predictors of under reporting in Malaysia. Pharmacoepidemiol Drug Saf. 2007;16(2):223-8.

17. Van Grootheest AC, Van Puijenbroek EP, De Jongvan den Berg LTW. Contribution of Pharmacists to the reporting of adverse drug reactions. Pharmacoepidemiol Drug saf. 2002;11(3):205-10.

18. Oreagba IA. Pharmacovigilance and the role of the Hospital and Community Pharmacists. The Nigerian j of Pharm. 2009;42(2):24-8.

19. Gedde-Dahl A, Harg P, Stenberg-Nilson H, Buajordet M, Granas AG, Horn AM. Characteristics and quality of adverse drug reaction reports by pharmacists in Norway. Pharmacoepidemoil Drug Saf. 2007;16.: 999-1005

20. Kees VG, Oleson S, Couper M, deJong-vandenBerg L. Pharmacists role in reporting Adverse Drug Reactions in an international Perspective. Pharmacoepidemiol. Drug Saf. 2004; 13, 457-464.
21. Oreagba IA, Ogunleye 01 , Olayemi SO. The knowledge, perception and practice of Pharmacovigilance in Lagos state, South West Nigeria. Pharmacopidemiol Drug Saf. 2011; 20, $30-35$

22. SU C, Ji H, Su Y. Hospital Pharmacists' knowledge and opinion regarding adverse drug reaction reporting in Northern China. Pharmacoepidemiol. Drug Saf. 2010; 19, 217-222.

23. Toklu HZ, Uysal MK. The knowledge and attitude of the Turkish community pharmacists toward pharmacovigilance in the Kadikoy district of Istanbul. Pharm World Sci. 2008;30, 556-562.

24. Lee KK, Chan TY, Raymond K, Critichley JA. Pharmacists' attitudes toward adverse drug reaction reporting in Hong Kong Ann Pharmacother. 1994; 28 : $1400-1403$

25. Okezie OO, Fawole O.I. Adverse drug reaction reporting by physicians in Ibadan, Nigeria. Pharmacoepidemiol. Drug Saf. 2008; 17:517 - 522.

26. Irugo M, Beitia G, Bes-Rastrollo M, Figueiras A, Hernandez-Diaz S, Lasheras $B$. Factors that influence under-reporting of suspected adverse drug reactions among Community Pharmacists in a Spanish region. Drug Saf. 2007; 30: $1073-1082$.

27. American Society of Health-System Pharmacists. ASHP guidelines on adverse drug reaction monitoring and reporting 1995; 52 (4) 417-419

28. Zolezzi $\mathrm{M}$ and Parsotam N. Adverse drug reaction reporting in New Zealand: implications for pharmacists Therapeutics and Clinical Risk Management 2005: 1(3) $181-188$

29. Koch KE . Adverse Drug Reactions In: Brown TR, ed. Handbook of Institutional Pharmacy Practice. 3rd ed. Bethesda.MD. American society of Hospital Pharmacists. 1992; 279-291 